\title{
Metastatic duodenal germ cell tumor diagnosed with endoscopic ultrasound
}
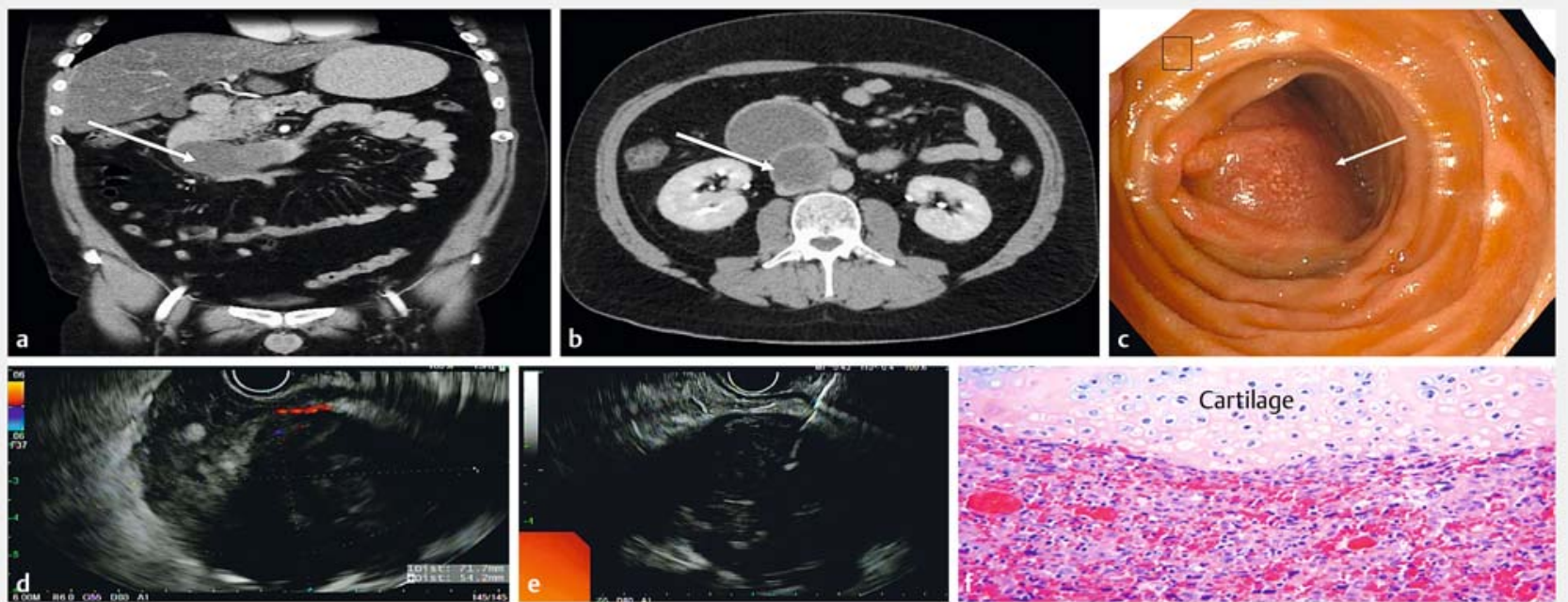

- Fig. 1 Evaluation and diagnosis of a retroperitoneal mass. a Coronal computed tomography (CT) of the abdomen showed a retroperitoneal mass (arrow). b Transverse CT of the abdomen showed the same mass (arrow). c Upper endoscopy showed a subepithelial near-obstructive mass (arrow) in the second portion of the duodenum. $\mathbf{d}$ Endoscopic ultrasound showed a $7 \times 5.4 \mathrm{~cm}$ solid cystic duodenal mass. e Fine-needle biopsy of the duodenal mass was performed. $\mathbf{f}$ Histology of the resected duodenal mass showed the presence of cartilage, consistent with mixed germ cell tumor.

Testicular tumors are the most common solid tumors reported in young males aged $15-35$ years $[1,2]$. These tumors frequently metastasize to retroperitoneal lymph nodes, but only $5 \%$ of these tumors seed the gastrointestinal (GI) tract $[3,4]$, with the duodenum being the least common site (1.4\%) [4]. Local extension from the retroperitoneal lymph node into the Gl tract is the common method of spread.

We report on a 44-year-old man with symptoms of gastric outlet obstruction. Computed tomography (CT) of the abdomen showed a bilobed retroperitoneal mass of $7 \times 5 \mathrm{~cm}$ compressing the duodenum, suspicious for duplication cyst ( Fig.1a,b). Esophagogastroduodenoscopy showed a subepithelial nearobstructive mass in the second portion of the duodenum, which appeared cystic on palpation with closed forceps ( Fig. 1 c). Endoscopic ultrasound (EUS) showed a $7 \times 5.4 \mathrm{~cm}$ solid cystic mass ( $\triangleright$ Fig.1d). Fine-needle biopsy (FNB) with a 22-gauge needle ( $\mathbf{F i g . 1} \mathbf{e}$ ) re-

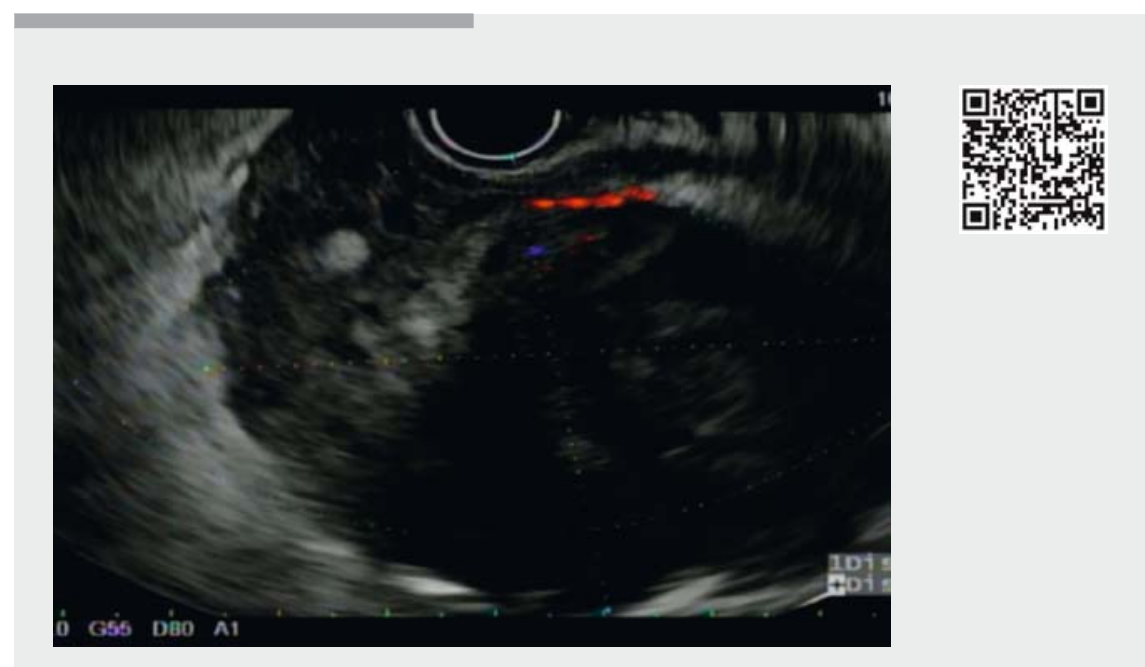

$\checkmark$ Video 1 A duodenal mass was evaluated by endoscopic ultrasound. Upon biopsy, the mass was shown to be a metastatic germ cell tumor from the testis.

vealed poorly differentiated epithelioid carcinoma, with unknown primary. Given the patient's age, testicular tumor was a highly likely differential diagnosis.
The patient underwent pancreas-sparing duodenal resection. Histology showed a mixed germ cell tumor with unusual presence of cartilage ( $>$ Fig. $1 \mathbf{f})$. Ultrasound of the testes showed a $1.7 \mathrm{~cm}$ 
right testicular mass, which was resected, and histology was consistent with mixed germ cell tumor. Staging revealed bony metastasis. The patient is currently undergoing chemotherapy.

This case highlights a testicular mixed germ cell tumor with metastasis to the duodenum, which is rare (1.4\%). In addition, hematogenous spread without the local involvement of the lymph nodes was noted, which is also a rare phenomenon. EUS-FNB confirmed a previously unsuspected malignancy, prompting a search for the primary and subsequent surgical management.

In young males with upper gastrointestinal tumors, metastasis from a testicular mass should always be considered. EUSFNB can provide valuable information.

Endoscopy_UCTN_Code_CCL_1AF_2AG_3AD

Competing interests

None

The authors

Nayana George ${ }^{1}$, Abhilash Perisetti ${ }^{2}$, Saikiran Raghavapuram ${ }^{1}$, Debdeep Banerjee ${ }^{3}$, Enoch Kuo ${ }^{4}$, Benjamin Tharian ${ }^{1}$

1 Division of Gastroenterology and Hepatology, Department of Internal
Medicine, University of Arkansas for Medical Sciences, Little Rock, Arkansas, United States

2 Department of Family and Community Medicine, Texas Tech University Health Sciences Center, Lubbock, Texas, United States

3 Department of Medicine, University of Florida College of Medicine, Gainesville, Florida, United States

4 Department of Pathology, University of Arkansas for Medical Sciences, Little Rock, Arkansas, United States

\section{Corresponding author}

\section{Saikiran Raghavapuram, MD}

Division of Gastroenterology and Hepatology, Department of Internal Medicine, University of Arkansas for Medical Sciences, 4301 West Markham, slot \# 509, Little Rock, AR-72205, United States

Fax: +1-501-526-4596

Saikiran6@gmail.com

\section{References}

[1] Konheim JA, Israel JA, Delacroix SE. Klinefelter syndrome with poor risk extragonadal germ cell tumor. Urol Case Rep 2016; 10: $1-3$

[2] Fu S, Avezbakiyev B, Zhi W et al. Germ cell cancer presenting as gastrointestinal bleeding and developing brain metastases: case report and review of the literature. Future Oncol 2012; 8: $1487-1493$
[3] Morinaga M, Osada T, Kon K et al. Metastatic seminoma in the duodenum: diagnosis with endoscopy followed by successful treatment. Intern Med 2014; 53: 2777 - 2781

[4] Bain AJ, Owens DJ, Savides TJ. Image of the month. Upper gastrointestinal bleeding caused by metastatic testicular choriocarcinoma. Clin Gastroenterol Hepatol 2009; 8: A22

\section{Bibliography}

DOI https://doi.org/10.1055/s-0043-119979

Published online: 10.11.2017

Endoscopy 2018; 50: E27-E28

(c) Georg Thieme Verlag KG

Stuttgart · New York

ISSN 0013-726X

\section{ENDOSCOPY E-VIDEOS}

https://eref.thieme.de/e-videos

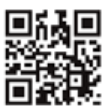

Endoscopy E-Videos is a free access online section, reporting on interesting cases and new

techniques in gastroenterological endoscopy. All papers include a high quality video and all contributions are freely accessible online.

This section has its own submission website at https://mc.manuscriptcentral.com/e-videos 